\title{
Computer Aided Education on Flexible Transmission Systems
}

\author{
P. S. Georgilakis and G. N. Korres
}

\begin{abstract}
This paper demonstrates how Mathcad software can be used as a major advancement for teaching flexible AC transmission systems (FACTS). Mathcad, thanks to its efficient presentation and computation capabilities, holds strong potential as a teaching tool for engineering education. The advantages of the proposed approach are: (i) the students write the equations in the familiar textbook format, (ii) the students' interest is significantly increased because the problems are interactively solved in a computer-equipped classroom, and (iii) the students concentrate on the meaning of what they learn, they analyze results and draw conclusions, thus enhancing their learning ability. The methods described in this paper have been proven very efficient in the education of students studying FACTS at the National Technical University of Athens (NTUA), Greece. The work presented in this paper advances the use of computer application in the education of FACTS.
\end{abstract}

Index Terms-- Flexible AC transmission systems (FACTS), Mathcad, power engineering education, power systems, static synchronous series compensator (SSSC), transmission lines.

\section{INTRODUCTION}

$\mathrm{M}$ ODERN transmission systems are undergoing continuous changes and restructuring. The regulatory constraints on transmission expansion have pushed transmission systems closer to their stability and thermal limits. To achieve both operational reliability and financial profitability, it is clear that more efficient utilization and control of the existing transmission system infrastructure is required. This can be effectively tackled by the introduction of high power electronic controllers for the flexible regulation of power flows and voltages in $\mathrm{AC}$ transmission systems, whereby the changes can be accommodated easily without stressing the system. Power electronic based systems and other static equipment, which provide controllability of power flows and voltages, are termed flexible AC transmission systems (FACTS) [1]. The basic applications of FACTS controllers are: power flow control, increase of transmission capability, voltage control, reactive power compensation, stability improvement, power quality improvement, and interconnection of renewable and distributed generation. In the fast changing electricity market environment, teaching transmission lines and FACTS controllers is a challenge.

P. S. Georgilakis and G. N. Korres are with the School of Electrical and Computer Engineering, National Technical University of Athens (NTUA), Athens, Greece (e-mail: pgeorg@power.ece.ntua.gr).
Mathcad software [2] is widely used for electrical engineering topics [3]-[5]. The students learn how to use Mathcad in a short time with limited practice. Its use is much easier than learning a programming language and has many built-in functions that facilitate its use in many textbook applications. Its main advantage is that the equations appear in similar format as in handwriting. The Mathcad feature of what-you-see-is-what-you-get, allows students to see if they have entered a problem correctly or not. Another significant advantage is the integration of the units of measurement, which means that the students are free from keeping track of the units used. The students have only to indicate the units for each input data and ask for the answer in any particular unit, while Mathcad automatically performs all the unit transformations. Taking advantage of the computational power and speed of Mathcad, instructors and students can quickly cycle through problem scenarios, observing changes in the behavior of transmission lines and FACTS controllers.

This paper proposes the use of Mathcad as a teaching and learning tool in transmission lines and FACTS. Moreover, the students can use Mathcad to solve their homework and better understand the subject matter. The proposed approach has been tested and applied at the NTUA for teaching an undergraduate course on transmission lines and FACTS. The course content and syllabus is presented in Section II. Although all subjects of this course have been implemented and taught using Mathcad, due to space limitations, one practical example is provided in the paper, emphasizing the use of Mathcad to simplify the material presented in class. More specifically, the impact of static synchronous series compensator (SSSC) on transmission line power flow control is analyzed in Section III. The problem is solved using Mathcad and the respective code, presented in the Appendix, is discussed in Section III. The student feedback is presented in Section IV. The experience has shown that the students' interest is increased and their problem solving ability is improved with the introduction of the interactive Mathcad-based problem solving in a computer equipped classroom.

\section{COURSE Content AND Syllabus}

One of the seventh semester elective courses, of the fiveyear NTUA undergraduate curriculum for Electrical and Computer Engineers, is on transmission lines and FACTS controllers and covers the following topics:

- Introduction to Mathcad;

- Electrical characteristics of transmission lines (TL); 
- Equations and equivalent circuits of small, medium, and long TL;

- Generalized circuit ABCD constants and two-port circuits of TL;

- TL shunt and series compensation;

- TL power, losses, and efficiency;

- Introduction to FACTS;

- FACTS with thyristor based controllers:

- Static VAr compensators (SVC);

- Thyristor controlled series capacitors (TCSC);

- $\quad$ Phase shifters (PS);

- FACTS controllers with voltage- or current-sourced converters:

- Static synchronous compensators (STATCOM);

- Static synchronous series compensators (SSSC);

- Unified power flow controllers (UPFC);

- Interline power flow controllers (IPFC);

- High voltage direct current (HVDC) transmission systems;

- The role of FACTS in deregulated electricity markets.

\section{Power Flow Control of Transmission Line With} SSSC

\section{A. Theoretical Analysis}

Fig. 1 shows an SSSC connected in series with a lossless short transmission line between sending-end $\mathrm{S}$ and receiving-end $\mathrm{R}$. The transmission line has an inductive series reactance per phase, $X$, a voltage source, $V_{S}=\left|V_{S}\right| \angle \delta$, at the sending-end, and a voltage source, $V_{R}=\left|V_{R}\right| \angle 0^{0}$, at the receiving-end, respectively. The SSSC is emulated by an injected controllable voltage source, $V_{T}$, located between buses $\mathrm{S}$ and $\mathrm{R}$, in such a way that is split into two parts, $X_{1}$ and $X_{2}$, and $X=X_{1}+X_{2}$. The voltages at the terminal ends of the SSSC are defined by $V_{A}$ and $V_{B}$. All electrical variables are represented in the per unit system.

The phase angle of voltage $V_{T}$ may be shifted by $\mp 90^{\circ}$ with regard to the line current $I$, which implies that:

$$
V_{T}=\mp j \frac{I}{|I|}\left|V_{T}\right|=\mp\left|V_{T}\right| \frac{\left(V_{S}-V_{R}\right)}{\left|V_{S}-V_{R}\right|}
$$

where the positive sign denotes an inductive operation mode, while the negative sign denotes a capacitive operation mode.

From Kirchhoff's voltage law (KVL) we obtain:

$$
V_{S}-V_{R}=j X I+V_{T}
$$

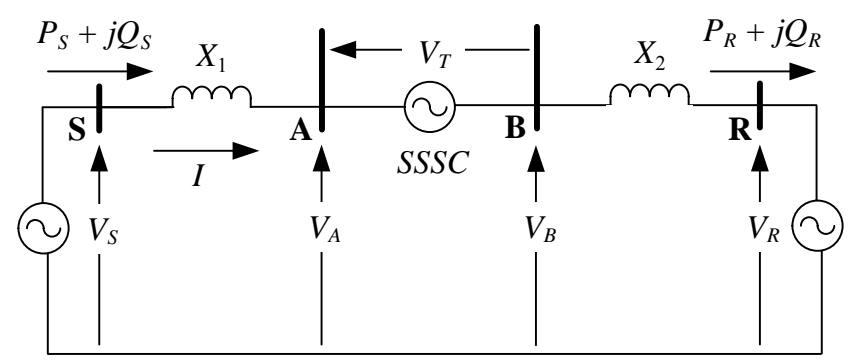

Fig. 1. Representation of a short transmission line with an SSSC.

Substituting (1) into (2) we have:

$$
I=\frac{\left(V_{S}-V_{R}\right)}{j X}\left(1 \pm \frac{\left|V_{T}\right|}{\left|V_{S}-V_{R}\right|}\right)
$$

Since $V_{S}=\left|V_{S}\right| \angle \delta$ and $V_{R}=\left|V_{R}\right| \angle 0^{0}$ we have:

$$
V_{S}-V_{R}=\left(\left|V_{S}\right| \cos \delta-\left|V_{R}\right|\right)+j\left|V_{S}\right| \sin \delta
$$

From (4) we derive the magnitude of $\left|V_{S}-V_{R}\right|$ as:

$$
\left|V_{S}-V_{R}\right|=\sqrt{\left|V_{S}\right|^{2}+\left|V_{R}\right|^{2}-2\left|V_{S}\right|\left|V_{R}\right| \cos \delta}
$$

Substitution of (4) and (5) into (3) gives:

$$
I=\frac{\left[\left(\left|V_{S}\right| \cos \delta-\left|V_{R}\right|\right)+j\left|V_{S}\right| \sin \delta\right]}{j X} E
$$

where:

$$
E=1 \pm \frac{\left|V_{T}\right|}{\sqrt{\left|V_{S}\right|^{2}+\left|V_{R}\right|^{2}-2\left|V_{S}\right|\left|V_{R}\right| \cos \delta}}
$$

The active power $P_{S}$ and reactive power $Q_{S}$ at the sending-end of the line is:

$$
\begin{aligned}
& P_{S}=\operatorname{Re}\left[V_{S} I^{*}\right]=\operatorname{Re}\left[\left(\left|V_{S}\right| \cos \delta+\mathrm{j}\left|V_{S}\right| \sin \delta\right) I^{*}\right] \\
& Q_{S}=\operatorname{Im}\left[V_{S} I^{*}\right]=\operatorname{Im}\left[\left(\left|V_{S}\right| \cos \delta+\mathrm{j}\left|V_{S}\right| \sin \delta\right) I^{*}\right]
\end{aligned}
$$

where $I^{*}$ is the conjugate of the complex current $I$. Substitution of (6) into (8) and (9) gives:

$$
\begin{gathered}
P_{S}=\frac{\left|V_{S} \| V_{R}\right| \sin \delta}{X} E \\
Q_{S}=\frac{\left(\left|V_{S}\right|^{2}-\left|V_{S}\right|\left|V_{R}\right| \cos \delta\right)}{X} E
\end{gathered}
$$

The active power $P_{R}$ and reactive power $Q_{R}$ at the receiving-end is:

$$
\begin{aligned}
& P_{R}=\operatorname{Re}\left[V_{R} I^{*}\right]=\operatorname{Re}\left[\left|V_{R}\right| I^{*}\right] \\
& Q_{R}=\operatorname{Im}\left[V_{R} I^{*}\right]=\operatorname{Im}\left[\left|V_{R}\right| I^{*}\right]
\end{aligned}
$$

Substitution of (6) into (12) and (13) gives:

$$
P_{R}=\frac{\left|V_{S} \| V_{R}\right| \sin \delta}{X} E
$$




$$
Q_{R}=\frac{\left(\left|V_{S}\right|\left|V_{R}\right| \cos \delta-\left|V_{R}\right|^{2}\right)}{X} E
$$

From (10) and (14) we have $P_{S}=P_{R}$, due to the lossless short line model used. The maximum power transfer through the line without the SSSC is computed by setting $\left|V_{S}\right|=\left|V_{R}\right|=1 \mathrm{pu},\left|V_{T}\right|=0.0 \mathrm{pu}$, and $\delta=90^{\circ}$ in (10):

$$
P_{m}=\frac{1}{X}
$$

Dividing (10) by (16), the ratio of the transmitted power over maximum power is obtained:

$$
R T=\left|V_{S}\right|\left|V_{R}\right| E \sin \delta
$$

From KVL we obtain the voltages at the terminal ends of the SSSC:

$$
\begin{gathered}
V_{A}=V_{S}-j X_{1} I=\left|V_{S}\right| \angle \delta-j X_{1} I \\
V_{B}=V_{A}-V_{T}
\end{gathered}
$$

\section{B. The Problem and the Solution using Mathcad}

We assume that the transmission line of Fig. 1 has $X=1.0 \mathrm{pu}$ and an SSSC is connected in the middle of the line $\left(X_{1}=X_{2}=0.5 \mathrm{pu}\right)$. The voltage magnitudes at nodes $\mathrm{S}$ and $\mathrm{R}$ are $\left|V_{S}\right|=1.0 \mathrm{pu}$ and $\left|V_{R}\right|=0.97 \mathrm{pu}$, respectively.

1. If $\left|V_{T}\right|=0.6 \mathrm{pu}$ and $\delta=90^{\circ}$, compute the active and reactive power at the sending-end, the reactive power at the receiving-end, the line current, and the complex voltages $V_{T}, V_{A}$, and $V_{B}$, for the capacitive operation mode.

2. Calculate the ratio of transmitted power over maximum power $\left(R T_{i, n}\right)$, for the capacitive or inductive operation mode $\left(\left|V_{T}\right|=0.6 \mathrm{pu}\right)$ and the uncompensated mode $\left(\left|V_{T}\right|=0.0 \mathrm{pu}\right.$ ), and $i=226$ different values of angle $\delta$ (from $\delta_{i}=-45^{0}$ to $\delta_{i}=180^{\circ}$ with $1^{0}$ step). Moreover, calculate $R T$ for $\delta=-43^{\circ}$ and $\delta=143^{\circ}$ for the above three modes.

3. Calculate the values of $\delta$ in the interval $\left(-45^{\circ}, 225^{\circ}\right)$ where $R T$ is zero, for the inductive operation mode.

The solution of this problem using Mathcad can be found in the Appendix. More specifically, the response to question 1, i.e., the values of $P_{S}, Q_{S}, Q_{R}$, and $I$ are computed using equations (10), (11), (15), and (6), respectively, while the voltages $V_{T}, V_{A}$, and $V_{B}$ are computed using equations (1), (18), and (19), respectively. Moreover, Fig. 2 shows the variation of $P_{S}, Q_{S}$, and $Q_{R}$ as a function of the transmission angle $\delta$ for $\left|V_{T}\right|=0.6 \mathrm{pu}$ (capacitive operation mode).

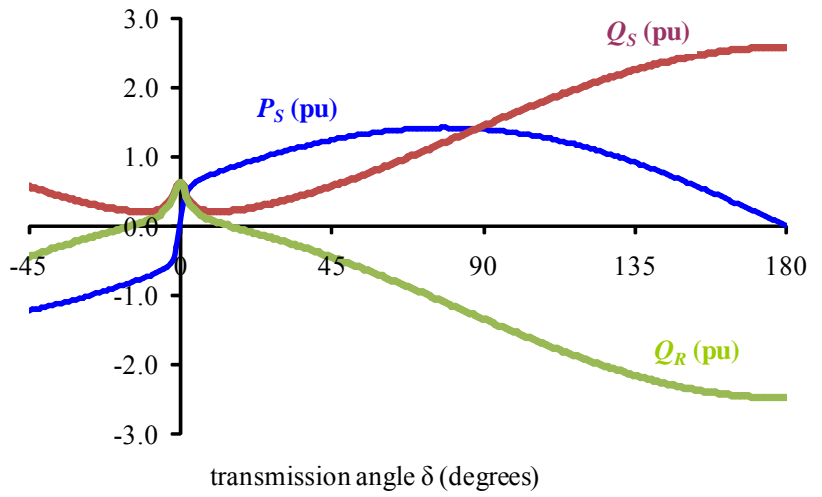

Fig. 2. Variation of $P_{S}, Q_{S}$, and $Q_{R}$ as a function of the transmission angle $\delta$ for $\left|V_{T}\right|=0.6 \mathrm{pu}$ and capacitive mode.

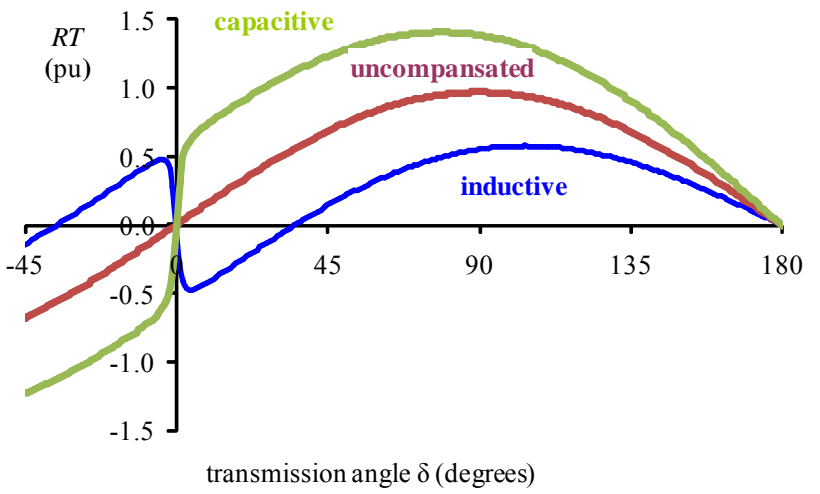

Fig. 3. Ratio of transmitted power over maximum power ( $R T$ ) as a function of the transmission angle $\delta$, for capacitive mode $\left(\left|V_{T}\right|=0.6 \mathrm{pu}\right)$, uncompensated mode $\left(\left|V_{T}\right|=0.0 \mathrm{pu}\right)$, and inductive mode $\left(\left|V_{T}\right|=0.6 \mathrm{pu}\right)$.

The response to question 2, i.e., the calculation of the ratio of transmitted power over maximum power, requires the formation of the two-dimensional matrix $R T_{i, n}$, where its rows $i$ correspond to the 226 different values of transmission angle $\delta$ and its columns $n$ correspond to the three operation modes (capacitive, uncompensated, inductive). The variable $R T_{i, n}$ is computed using equation (17). Fig. 3 plots the variable $R T$ as a function of $\delta$, for the three operation modes. The response to question 3, i.e., the calculation of the values of $\delta$ for which $R T$ becomes zero, is implemented with the use of solve built-in function of Mathcad, as shown in the Appendix.

\section{Student FeEdBack}

The educational example of Section III is one of the many examples that have been used during the last six years at the National Technical University of Athens (NTUA) to help teaching the undergraduate course of transmission lines and FACTS controllers. The educational example of Section III together with many additional examples not presented in this paper due to space limitations, are distributed to the students at the beginning of the semester, with detailed presentation of the calculations involved together with Mathcad files that perform the necessary computations. 
TABLE I

QuESTIONNAIRE AND AVERAGE EVALUATION

\begin{tabular}{|c|c|}
\hline Question & Score \\
\hline Is the prerequisite knowledge covered by other already taught courses? $(1=$ insufficiently, $5=$ average, $10=$ absolutely $)$ & 7.34 \\
\hline Is the content of the course taught in other courses? $(1=$ no, $5=$ at $50 \%, 10=$ at $100 \%$ i.e. nothing is new in this course $)$ & 2.29 \\
\hline Number of teaching hours for covering the course content ( $1=$ insufficient, $5=$ reasonable, $10=$ excessive $)$ & 5.26 \\
\hline Quantity of the necessary homework ( $1=$ insufficiently, $5=$ reasonable, $10=$ excessive) & 5.15 \\
\hline Organization of the course $(1=$ most negative, $10=$ most positive $)$ & 8.57 \\
\hline Interest of the course based on its content $(1=$ most negative, $10=$ most positive $)$ & 8.17 \\
\hline Communicativeness of the teachers $(1=$ most negative, $10=$ most positive $)$ & 8.32 \\
\hline Usefulness of the practical computer examples in understanding the course $(1=$ most negative, $10=$ most positive $)$ & 8.94 \\
\hline Reliability of the teachers in their educational obligations ( $1=$ most negative, $10=$ most positive) & 8.45 \\
\hline Adequacy and usefulness of the educational materials $(1=$ most negative, $10=$ most positive $)$ & 7.85 \\
\hline
\end{tabular}

For example, the teaching of the educational example of Section III is implemented as follows. The instructor presents in the class all the necessary theory of power flow control of transmission line with SSSC. As a laboratory exercise, the students solve the educational example of Section III using the Mathcad code of the Appendix in a lab with 48 computers. Groups of 48 students are formed and each student uses one of the lab computers to solve the example of Section III. The instructor, aided by four advanced postgraduate students, facilitates the students to solve the educational example.

The Electrical and Computer Engineering students at NTUA are well familiar with computers and Mathcad at their seventh semester of studies, when the transmission lines and FACTS controllers course is taught. Students indicated that the Mathcad-based educational examples allow them to clearly understand the issues of transmission lines and FACTS controllers. They appreciated their active involvement, since they solved almost alone the complete problems of transmission lines and FACTS controllers, from the beginning to the end. The experience they gain allows them to easily solve their exercises and perform better at the exams of the course. It is also important that the interest of students for this course was increased thanks to the introduction of computeraided education methodology.

The students learnt very easily to use Mathcad software thanks to its powerful user interface, where the equations are written in the familiar textbook format, and due to their experience with computers.

This computer-aided education approach was assessed both formally with student evaluations and informally from discussions with students. It should be noted that students rated the education material and the software positively and course evaluations were higher after these tools were introduced. The formal evaluation of the courses through a standard questionnaire is a common practice in the School of Electrical and Computer Engineering of NTUA. This questionnaire is composed of ten questions: the first six questions are related with the course and the last four questions are related with the teachers and the educational materials. Table I shows the average score for each question from the feedback of 35 students during the academic year 2010-2011. It can be seen that the students rate very high the usefulness of the practical computer examples in understanding the course.

An increase was observed in the number of students that choose the transmission lines and FACTS controllers course to elaborate their Diploma dissertation. All these findings provide incentives for implementing similar computer-aided education methodologies to other courses as well.

\section{CONCLUSIONS}

This paper presents an effective approach to education in the field of transmission lines and FACTS. The proposed teaching methodology uses Mathcad, a powerful tool for performing calculations. Mathcad has been used during the last six years at the National Technical University of Athens, to help teaching the undergraduate course of transmission lines and FACTS. 
The classroom experience at NTUA has shown that the interest of students has been increased and the problem solving ability has been improved. These results can be attributed to Mathcad's capacility in writing mathematical equations in a form similar to their appearance in textbooks, providing an immediate visual feedback to the student.

\section{APPENDIX: MATHCAD CODE FOR POWER FLOW CONTROL} OF TRANSMISSION LINE WITH SSSC

\section{Definition $\quad \mathrm{pu}:=1.0$}

\section{Input Data}

$$
\begin{array}{ll}
\mathrm{X}:=1.0 \cdot \mathrm{pu} & \mathrm{X}_{1}:=\frac{\mathrm{X}}{2} \\
\mathrm{X}_{2}:=\frac{\mathrm{X}}{2} & \delta:=90 \cdot \mathrm{deg} \\
\mathrm{V}_{\mathrm{S}}:=1.0 \cdot \mathrm{e}^{\mathrm{j} \cdot \delta} \cdot \mathrm{pu} & \mathrm{V}_{\mathrm{R}}:=0.97 \cdot \mathrm{e}^{\mathrm{j} \cdot 0} \cdot \mathrm{pu}
\end{array}
$$

\section{Response to Question 1}

Calculation of the active and reactive power at the sendingend $\left(\mathrm{P}_{\mathrm{S}}, \mathrm{Q}_{\mathrm{S}}\right)$ and the receiving-end $\left(\mathrm{P}_{\mathrm{R}}, \mathrm{Q}_{\mathrm{R}}\right)$, the current ( I), and the voltages $\mathrm{V}_{\mathrm{A}}, \mathrm{V}_{\mathrm{T}}$, and $\mathrm{V}_{\mathrm{B}}$.

\section{$\underline{\text { Additional Input Data }}$}

$\mathrm{V}_{\mathrm{T}}:=0.6 \cdot \mathrm{pu}$ (capacitive operation mode)

\section{$\underline{\text { Calculations }}$}

$$
\begin{aligned}
& \mathrm{E}:=1+\frac{\left|\mathrm{V}_{\mathrm{T}}\right|}{\sqrt{\left(\left|\mathrm{V}_{\mathrm{S}}\right|\right)^{2}+\left(\left|\mathrm{V}_{\mathrm{R}}\right|\right)^{2}-2 \cdot\left|\mathrm{V}_{\mathrm{S}}\right| \cdot\left|\mathrm{V}_{\mathrm{R}}\right| \cdot \cos (\delta)}} \\
& \mathrm{P}_{\mathrm{S}}:=\frac{\left|\mathrm{V}_{\mathrm{S}}\right| \cdot\left|\mathrm{V}_{\mathrm{R}}\right| \cdot \sin (\delta)}{\mathrm{X}} \cdot \mathrm{E} \quad \mathrm{P}_{\mathrm{R}}:=\mathrm{P}_{\mathrm{S}} \\
& \mathrm{Q}_{\mathrm{S}}:=\frac{\left[\left(\left|\mathrm{V}_{\mathrm{S}}\right|\right)^{2}-\left|\mathrm{V}_{\mathrm{S}}\right| \cdot\left|\mathrm{V}_{\mathrm{R}}\right| \cdot \cos (\delta)\right]}{\mathrm{X}} \mathrm{E} \\
& \mathrm{Q}_{\mathrm{R}}:=\frac{\left.|| \mathrm{V}_{\mathrm{S}}|\cdot| \mathrm{V}_{\mathrm{R}} \mid \cdot \cos (\delta)-\left(\left|\mathrm{V}_{\mathrm{R}}\right|\right)^{2}\right]}{\mathrm{X}} \mathrm{E} \\
& \mathrm{I}:=\frac{\left[\left(\left|\mathrm{V}_{\mathrm{S}}\right| \cdot \cos (\delta)-\left|\mathrm{V}_{\mathrm{R}}\right|\right)+\mathrm{j} \cdot\left|\mathrm{V}_{\mathrm{S}}\right| \cdot \sin (\delta)\right]}{\mathrm{jX}} \cdot \mathrm{E} \\
& \mathrm{V}_{\mathrm{A}}:=\mathrm{V}_{\mathrm{S}}-\mathrm{j} \cdot \mathrm{X}_{1} \cdot \mathrm{I} \\
& \mathrm{V}_{\mathrm{T}}:=-\mathrm{j} \cdot \frac{\mathrm{I}}{|\mathrm{I}|} \cdot\left|\mathrm{V}_{\mathrm{T}}\right| \quad \mathrm{V}_{\mathrm{B}}:=\mathrm{V}_{\mathrm{A}}-\mathrm{V}_{\mathrm{T}}
\end{aligned}
$$

\section{$\underline{\text { Results }}$}

$$
\begin{array}{ll}
\mathrm{E}=1.431 \cdot \mathrm{pu} & \\
\mathrm{P}_{\mathrm{S}}=1.388 \cdot \mathrm{pu} & \mathrm{Q}_{\mathrm{S}}=1.431 \cdot \mathrm{pu} \\
\mathrm{P}_{\mathrm{R}}=1.388 \cdot \mathrm{pu} & \mathrm{Q}_{\mathrm{R}}=-1.346 \cdot \mathrm{pu} \\
|\mathrm{I}|=1.99 \cdot \mathrm{pu} & \arg (\mathrm{I})=44 \cdot \mathrm{deg} \\
\left|\mathrm{V}_{\mathrm{A}}\right|=0.75 \cdot \mathrm{pu} & \arg \left(\mathrm{V}_{\mathrm{A}}\right)=22 \cdot \mathrm{deg} \\
\left|\mathrm{V}_{\mathrm{T}}\right|=0.6 \cdot \mathrm{pu} & \arg \left(\mathrm{V}_{\mathrm{T}}\right)=-46 \cdot \operatorname{deg} \\
\left|\mathrm{V}_{\mathrm{B}}\right|=0.77 \cdot \mathrm{pu} & \arg \left(\mathrm{V}_{\mathrm{B}}\right)=69 \cdot \operatorname{deg}
\end{array}
$$

\section{Response to Question 2}

Calculation of the ratio of transmitted power over maximum power $\left(\mathrm{RT}_{\mathrm{i}, \mathrm{n}}\right)$ considering 3 different values of $\mathrm{V}_{\mathrm{T}}\left(\mathrm{VT}_{\mathrm{n}}\right)$ and 226 different values of angle $\delta\left(\delta_{i}\right)$. Moreover, calculation of RT for $\delta=-43^{\circ}$ and $\delta=143^{\circ}$ for the 3 different values of $\mathrm{V}_{\mathrm{T}}$.

\section{Calculations}

$$
\begin{aligned}
& \mathrm{i}:=0,1 . .225 \quad \mathrm{n}:=0,1 . .2 \\
& \mathrm{VT}_{\mathrm{n}}:=-0.6+0.6 \mathrm{n} \quad \delta_{\mathrm{i}}:=(-45+\mathrm{i}) \cdot \mathrm{deg} \\
& \mathrm{E}_{\mathrm{i}, \mathrm{n}}:=1+\frac{\mathrm{VT}_{\mathrm{n}}}{\sqrt{\left(\left|\mathrm{V}_{\mathrm{S}}\right|\right)^{2}+\left(\left|\mathrm{V}_{\mathrm{R}}\right|\right)^{2}-2 \cdot\left|\mathrm{V}_{\mathrm{S}}\right| \cdot\left|\mathrm{V}_{\mathrm{R}}\right| \cdot \cos \left(\delta_{\mathrm{i}}\right)}} \\
& \mathrm{RT}_{\mathrm{i}, \mathrm{n}}:=\left|\mathrm{V}_{\mathrm{S}}\right| \cdot\left|\mathrm{V}_{\mathrm{R}}\right| \cdot \mathrm{E}_{\mathrm{i}, \mathrm{n}} \cdot \sin \left(\delta_{\mathrm{i}}\right)
\end{aligned}
$$

$\underline{\text { Results }}$

\section{Inductive mode}

$$
\begin{array}{ll}
\delta_{2}=-43 \cdot \operatorname{deg} & \mathrm{RT}_{2,0}=-0.112 \cdot \mathrm{pu} \\
\delta_{188}=143 \cdot \mathrm{deg} & \mathrm{RT}_{188,0}=0.396 \cdot \mathrm{pu} \\
& \\
& \underline{\mathrm{Uncompensated}} \\
& \mathrm{VT}_{1}:=0.0 \cdot \mathrm{pu} \\
\delta_{2}=-43 \cdot \operatorname{deg} & \mathrm{RT}_{2,1}=-0.662 \cdot \mathrm{pu} \\
\delta_{188}=143 \cdot \operatorname{deg} & \mathrm{RT}_{188,1}=0.584 \cdot \mathrm{pu}
\end{array}
$$

\section{$\underline{\text { Capacitive mode }}$}

$$
\begin{array}{ll}
\delta_{2}=-43 \cdot \operatorname{deg} & \mathrm{RT}_{2,2}=-1.211 \cdot \mathrm{pu} \\
\delta_{188}=143 \cdot \mathrm{deg} & \mathrm{RT}_{188,2}=0.771 \cdot \mathrm{pu}
\end{array}
$$




\section{Response to Question 3}

Calculation of the values of $\delta$ in the interval $\left(-45^{\circ}, 225^{\circ}\right)$ where RT becomes zero, for $\mathrm{V}_{\mathrm{T}}=0.6 \mathrm{pu}$ (inductive operation mode).

\section{$\underline{\text { Calculations }}$}

$$
\mathrm{V}_{\mathrm{S}}:=\left|\mathrm{V}_{\mathrm{S}}\right|=1
$$$$
\left[1+\frac{\mathrm{VT}_{0}}{\sqrt{\left(\left|\mathrm{V}_{\mathrm{S}}\right|\right)^{2}+\left(\left|\mathrm{V}_{\mathrm{R}}\right|\right)^{2}-2 \cdot\left|\mathrm{V}_{\mathrm{S}}\right| \cdot\left|\mathrm{V}_{\mathrm{R}}\right| \cdot \cos (\mathrm{x})}}\right] \cdot\left|\mathrm{V}_{\mathrm{S}}\right| \cdot\left|\mathrm{V}_{\mathrm{R}}\right| \cdot
$$$$
\sin (\mathrm{x})=0 \mid \text { solve, } \mathrm{x} \text { assume, } \mathrm{x}=\text { RealRange }\left(-\frac{\pi}{4}, \frac{5 \pi}{4}\right) \rightarrow\left(\begin{array}{c}
0.61825 \\
-0.61825 \\
0 \\
3.14159
\end{array}\right)
$$

\section{$\underline{\text { Results }}$}

As can be seen above, the solve command of Mathcad found the following four values of $\delta$ :

$$
\begin{array}{ll}
\delta=0.61825 \cdot \mathrm{rad} & \delta=-0.61825 \cdot \mathrm{rad} \\
\delta=0.0 \cdot \mathrm{rad} & \delta=3.14159 \cdot \mathrm{rad}=\pi \cdot \mathrm{rad}
\end{array}
$$

for which the ratio RT of transmitted power over maximum power is zero.

\section{REFERENCES}

[1] N. G. Hingorani and L. Gyugyi, Understanding FACTS - Concepts and Technology of Flexible AC Transmission Systems. New York: IEEE Press, 2000.

[2] Mathcad 14 Users Guide, Parametric Technology Corp., MA 02494 USA.

[3] C. Domnisoru, "Using Mathcad in teaching power engineering," IEEE Trans. Education, vol. 48, no. 1, pp. 157-161, Feb. 2005.

[4] G. G. Karady and K. A. Nigim, "Improve learning efficiency by using general purpose mathematics software in power engineering," IEEE Trans. Power Syst., vol. 18, no. 3, pp. 979-985, Aug. 2003.

[5] K. A. Nigim and R. R. DeLyser, "Using Mathcad in understanding the induction motor characteristics," IEEE Trans. Education, vol. 44, no. 2, pp. 165-169, May 2001

\section{BIOGRAPHIES}

Pavlos S. Georgilakis received the Diploma and Ph.D. degrees in electrical and computer engineering from the National Technical University of Athens (NTUA), Athens, Greece, in 1990 and 2000, respectively. He is currently a Lecturer at the School of Electrical and Computer Engineering of NTUA. From 2004 to 2009, he was an Assistant Professor in the Production Engineering and Management Department of the Technical University of Crete, Greece. His current research interests include transmission and distribution of electric power.

George N. Korres received the Diploma and Ph.D. degrees in electrical and computer engineering from the National Technical University of Athens (NTUA), Athens, Greece, in 1984 and 1988, respectively. Currently he is Associate Professor with the School of Electrical and Computer Engineering of NTUA. His research interests are in power system state estimation, power system protection, and industrial automation. Prof. Korres is a member of CIGRE. 